\title{
Use of density functional theory for modeling optical properties of vacancy defects in nanoclusters of various SiC polytypes
}

\author{
O.A.Zhikol ${ }^{1}$, A.V.Luzanov ${ }^{1}$, I.V.Omelchenko ${ }^{1}$, \\ A.L.Pushkarchuk ${ }^{2,3}$, V.A.Pushkarchuk ${ }^{4}$, A.P.Nizovstev $^{5}$, \\ S.Ya.Kilin ${ }^{5}$, T.V.Bezyazychnaya ${ }^{2}$, S.A.Kuten, ${ }^{, 3}$ \\ ${ }^{1}$ SSI "Institute for Single Crystals", National Academy of Sciences of \\ Ukraine, 60 Nauky Ave., 61001 Kharkiv, Ukraine \\ ${ }^{2}$ Institute of Physical Organic Chemistry, 13 Surganov Str., \\ 220072 Minsk, Belarus \\ ${ }^{3}$ Institute for Nuclear Problems, Belarusian State University, \\ 11 Bobruiskaya Str., 220030 Minsk, Belarus \\ ${ }^{4}$ Belarusian State University Informatics and Radioelectronics, \\ 6 P.Brovka Str., 220013 Minsk, Belarus \\ ${ }^{5}$ B.I.Stepanov Institute of Physics, 68 Nezavisimosti Ave., \\ 220072 Minsk, Belarus
}

Received August 28, 2017

\begin{abstract}
We studied electronic properties of the ground and lowest excited states of SiC defective nanoclusters falling into $3 \mathrm{C}, 2 \mathrm{H}$ and $4 \mathrm{H}$ polymorphic types. The standard time-dependent DFT method was used along with the economical model-core-potential approximation. Basing on our earlier works, we performed the corresponding excited state structural analysis and show for the lowest triplet-triplet transition a significant effect of excitation localization in the defect vicinity.

Keywords: nanoparticles, carborundum polytypes, density functional theory, TDDFT, model core potentials, excited state localization.

Изучены әлектронные свойства основного и возбужденных состояний дефектных нанокластеров $\mathrm{SiC}$, относящихся к полиморфным типам $3 \mathrm{C}, 2 \mathrm{H}$ и $4 \mathrm{H}$. Использован стандартный времязависящий метод DFT совместно с экономичным приближением модельних остовных потенциалов. Основываясь на предыдущих наших исследованиях, проведен соответствующий структурный анализ возбужденных состояний и показано наличие значительной локализации возбуждения в окрестности дефекта для наинизших триплет-триплетных переходов.
\end{abstract}

Застосування теорії функціоналів густини до моделювання оптичних властивостей вакансійних дефектів у нанокластерах різних політипів SiC. О.А.Жикол, А.В.Лу занов, И.В.Олельченко, А.Л.Пушкарчук, В.А.Пушкарчук, А.П.Низовцев, С.Я.Килин, Т.В.Безязична, С.А.Кутень.

Вивчено електронні властивості основного та збуджених станів дефектних нанокластерів $\mathrm{SiC}$, котрі стосуються поліморфних типів $3 \mathrm{C}, 2 \mathrm{H}$ та $4 \mathrm{H}$. Використано стандартний часозалежний метод DFT у поєднанні з економічним наближенням модельних остовних потенціалів. Базуючись на попередніх наших дослідженнях, здійснено відповідний структурний аналіз збуджених станів та продемонстровано наявність значного ефекту локалізації збудження поблизу дефекту для найнижчих триплет-триплетних переходів. 

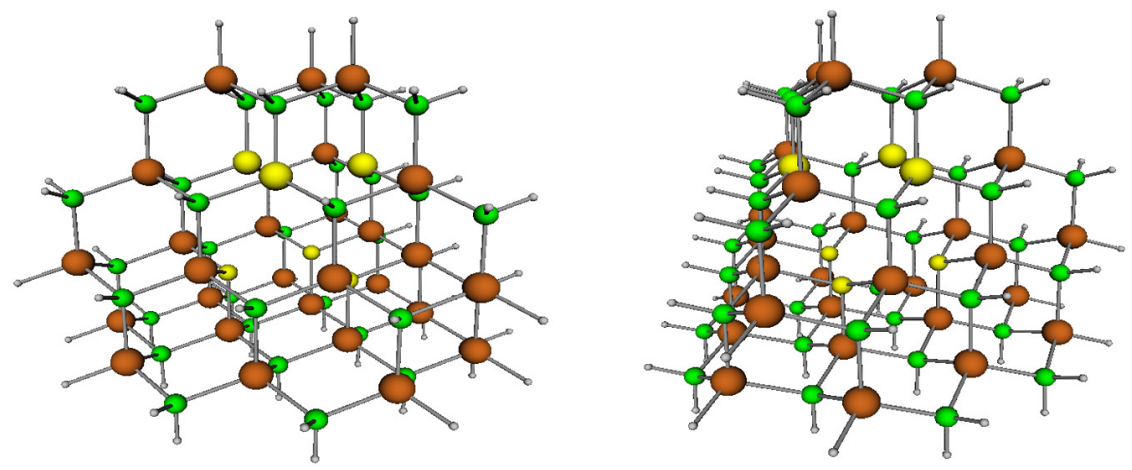

Fig. 1. Two projection views of $3 \mathrm{C}-\mathrm{SiC}$ nanocluster $\mathrm{Si}_{30} \mathrm{C}_{39} \mathrm{H}_{60}$ with $\mathrm{V}_{\mathrm{Si}}-\mathrm{V}_{\mathrm{C}}$ divacancy. The $\mathrm{Si}$ and $\mathrm{C}$ atoms are colored chocolate and lime, respectively; six dangling-bonds atoms are marked by yellow color.

\section{Introduction}

There is a large increase of interest in carbon containing nanoparticles as perspective materials for future quantum-computation devises [1-5]. In particular, photophysical and paramagnetic properties of the nanoparticles were broadly studied because of their important role in forming entangled quantum states (e. g., see [1, 5-8]). In our previous works we have investigated, mainly by semiempirical methods, various electronic properties of nanographenes [9, 10], nanodiamonds [11-15] and carborundum nanoparticles [16]. Specifically, density functional theory (DFT) was used for estimations of fine spin-spin interactions in the triplet ground state of diamond clusters with NV color centers $[11,12]$. In the present note, we compute and analyze low-lying triplet-triplet excitations in small defected nanoclusters of carborundum (nano-SiC for brevity).

\section{DFT modeling of electronic states in defective nano-SiC}

Current models of excited states in nanostructures are typically based on timedependent DFT (TDDFT) techniques [17], and our consideration follows this route as well. To this standard (but not without principal flaws [18]) approach we add here the excited state visual analysis previously proposed in [19-21]. More recently, the analysis, termed as the excited state structural analysis (ESSA) [20], was successfully applied to the paramagnetic color centers in nanodiamonds [13, 15].

For our study here we selected small clusters relating to cubic polytype $3 \mathrm{C}$, and hexagonal polytypes $2 \mathrm{H}$ and $4 \mathrm{H}$. For the given polytype, we started with the fragments of the regular SiC crystal lattice.
Surface dangling-bond atoms in the fragments were passivated, as usual, by hydrogen atoms. In this way we constructed three clusters of composition $\mathrm{Si}_{31} \mathrm{C}_{40} \mathrm{H}_{60} \quad(3 \mathrm{C}$ polytype), $\mathrm{Si}_{29} \mathrm{C}_{32} \mathrm{H}_{56}(2 \mathrm{H}$ polytype), and $\mathrm{Si}_{19} \mathrm{C}_{20} \mathrm{H}_{40}$ (4H polytype). The first one retains the $T_{d}$ symmetry, and others retain the $C_{3 y}$ symmetry. It is important that no close $\mathrm{H}$...H contacts take place in the resulting small clusters. These structures were used only as initial ones. Subsequently, the full optimization of geometrical parameters was carried out at the conventional B3LYP/6-31G $(\mathrm{d}, \mathrm{p})$ level. It produced quite reasonable bond lengths (1.875-1.895 ̊), with shorter bonds being closer to the cluster surface. The experimental Si-C bond lengths in the pristine carborundum structures are nearly $1.9 \AA$ [22].

The required defective systems were built from the above structures by removing either one silicon atom (monovacancy $\mathrm{V}_{\mathrm{Si}}$ ) or two connected atoms (divacancy $V_{S i}-V_{C}$ ). The defect was made in the respective cluster centroid; and no further geometrical optimization was performed. Notice that additional optimization would lead to a considerable distorsion of our not so large model clusters. However, in real large nanoparticles the analogous geometry relaxation should be sufficiently small. As a result of the simulations made, all final clusters with color defects possessed the $C_{3 v}$ symmetry, as it should be.

It is well established (e. g., see [23]) that the ground electronic state of the studied point defects is a spin-triplet state despite of a formally large number of dangling atoms (4 for $V_{S i}$, and 6 for $V_{S i}-V_{C}$ ). The selected example of nano-SiC with divacancy is shown in Fig. 1. 
Table 1. Squared total-spin expectation values, $<S^{2}>$, and Lowdin's spin densities, $\sigma_{\mathrm{C}}$ and $\sigma_{\mathrm{Si}}$, on dangling atoms for the ground triplet state of clusters with $\mathrm{V}_{\mathrm{Si}}-\mathrm{V}_{\mathrm{C}}$ at the CAM-B3LYP/MCP-DZP level

\begin{tabular}{|c|c|c|c||}
\hline Nanocluster & $<S^{2}>$ & $\sigma_{\mathrm{C}}$ & $\sigma_{\mathrm{Si}}$ \\
\hline $3 \mathrm{C}-\mathrm{SiC}$ & 2.027 & 0.531 & 0.001 \\
$2 \mathrm{H}-\mathrm{SiC}$ & 2.025 & 0.522 & 0.005 \\
$4 \mathrm{H}-\mathrm{SiC}$ & 2.026 & 0.517 & 0.003 \\
\hline
\end{tabular}

One difficult issue which we have grappled in this work is pertinent to mention now. It is a significant spin contamination in the ground unrestricted DFT state of the monovacancy clusters. In the case of all polytypes with $\mathrm{V}_{\mathrm{Si}}$ we obtained the expectation value of the squared total spin $<S^{2}>\approx 2.8$, instead of the correct value $<S^{2}>=2$. Recall that $<S^{2}>$, is a direct signature of the state spin-purity. Therefore, for our subsequent TDDFT studies, a poor spin-purity of the monovacancy ground states would preclude getting correct results for excited states. That is why we excluded all monovacancy structures from the subsequent study. As to nano-SiC with divacancy $\mathrm{V}_{\mathrm{Si}}-\mathrm{V}_{\mathrm{C}}$, we found that in all the cases studied, $\left\langle S^{2}>\approx 2\right.$ with sensible spin densities on dangling atoms near the divacancy (Table 1). Furthermore, we see from the Table that the spin density is gathered preferably on the carbon dangling atoms, that is in the divacancy vicinity.

At this place we have to make clear why in Table 1 we employed CAM-B3LYP method at the MCP-DZP level. The latter means that we exploit the model core potential (MCP) approximation along with double-zeta polarization (DZP) AO basis set. It is well known that atomic core electrons actually take no part in low-lying excitations, especially in neutral systems. Taking advantage of it, we chose an appropriate valence approximation (it is not a semiempirics!) of the MCP-DZP quality [24]. It per- mitted to effectively ignore two electrons from each $\mathrm{C}$ atom and ten electrons from each Si atom, thereby providing a considerable alleviation of our numerically cumbersome TDDFT problems.

\section{ESSA for nano-SiC excited states}

Now we consider the ESSA results for the lowest TDDFT electronic excitations in the selected SiC nanoclusters with divacancy. Recall that, ESSA [19, 20] treats the excited-state wave-function structure by using two kinds of atomic quantities, namely, excitation localization indexes $\left\{L_{A}^{*}\right\}$ and interatomic charge transfer (CT) numbers $\left\{l_{A \rightarrow B}\right\}$, where $A$ and $B$ are any atoms in the molecule under study. Localization index $\left\{L^{*}{ }_{A}\right\}$ gives a total probability of $A$ to be involved into the electronic excitation, whereas $\left\{l_{A \rightarrow B}\right\}$ presents a chosen probability of the electron transfer from $A$ to $B$ during the excitation. The two sets, $\left\{L_{A}^{*}\right\}$ and $\left\{l_{A \rightarrow B}\right\}$, are naturally normalized to unity, and furthermore $\left\{L_{A}^{*}\right\}$ can be explicitly expressed in terms of all possible $\left\{l_{A \rightarrow B}\right\}$ (for detail see [20,21]).

In our TDDFT computations of excited states, the 'spectroscopic' functional CAMB3LYP [25] and more contemporary functional M11 [26] were applied. As in the case of nanodiamonds with $\mathrm{NV}^{-}$color centers, the ground state of all defective nano-SiC has the ${ }^{3} A_{2}$ symmetry, and the lowest excitation has the ${ }^{3} E$ symmetry. It is important that as a result the utilized unrestricted TDDFT CAMB3LYP/MCP-DZP scheme predicted the correct lowest ${ }^{3} A_{2} \rightarrow{ }^{3} E$ transition (Table 2). It allowed us to use soundly the above-mentioned ESSA method for analyzing the obtained ${ }^{3} A_{2} \rightarrow{ }^{3} E$ transitions. The analysis was performed via the authors' ESSA code inserted in the GAMESS (US) computational chemistry program [27] which we applied for all presented calculations. In ESSA, one additional characteristic is also exploited. It is

Table 2. Calculated properties of ${ }^{3} A_{2} \rightarrow{ }^{3} E$ transition in clusters with divacancy: $\lambda$ is transition energy in $\mathrm{eV}$ (oscillator strength $f$ in parentheses); squared norm $\left\|(X, Y)_{\beta}\right\|^{2}$ is a full contribution of spin-down one-electron transitions to the total TDDFT excitation; $\kappa_{\text {TDDFT }}$ is a collectivity number; $L^{*}{ }_{3 \mathrm{Si}}$ is the excitation localization index for three Si dangling atoms, and $L^{*}{ }_{3 \mathrm{Si} i \mathrm{C}}$ is that for all 6 dangling atoms (both indexes in \%); $\mathrm{CT}_{\text {tot }}$ is a summary CT number (in \%); $R_{\text {exc }}$ in $\AA$.

\begin{tabular}{|r|c|c|c|c|c|c|c||}
\hline Cluster & $\lambda(f)$ & $\kappa_{\text {TDDFT }}$ & $\left\|(X, Y)_{\beta}\right\|^{2}$ & $L_{3 S i}^{*}$ & $L_{3 S i 3 C}^{*}$ & $\mathrm{CT}_{\text {tot }}$ & $R_{\text {exe }}$ \\
\hline $3 \mathrm{C}-\mathrm{SiC}$ & $1.284(0.03)$ & 1.07 & 0.980 & 21.1 & 64.5 & 92 & 3.89 \\
$2 \mathrm{H}-\mathrm{SiC}$ & $1.306(0.05)$ & 1.09 & 0.974 & 13.9 & 63.2 & 90 & 3.64 \\
$4 \mathrm{H}-\mathrm{SiC}$ & $1.283(0.03)$ & 1.07 & 0.977 & 18.7 & 64.6 & 92 & 3.63 \\
\hline
\end{tabular}



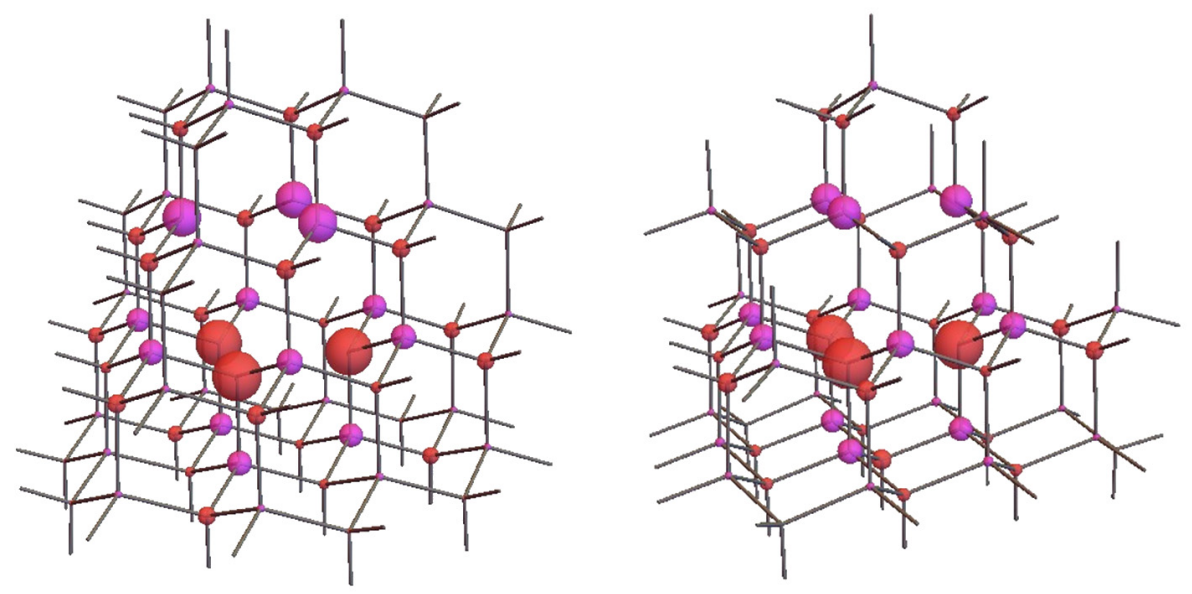

Fig. 2. Excitation localization diagrams in the 3C-SiC (the left panel) and $2 \mathrm{H}-\mathrm{SiC}$ (the right panel).

$\mathrm{C}$ and $\mathrm{Si}$ atoms are colored red and magenta, respectively.

the excitation radius $R_{e x c}$ which is but the average of all interatomic distances $\left\{R_{A, B}\right\}$ over CT distribution $\left\{l_{A \rightarrow B}\right\}$. The ESSA characteristics are also given in Table 2 .

We find that the computed ${ }^{3} A_{2} \rightarrow{ }^{3} E$ transition energy in $3 \mathrm{C}-\mathrm{SiC}$ is in excellent agreement with the bulk material DFT estimation $1.27 \mathrm{eV}$ from [23]. Moreover, the excitation radius turns out to be about a doubled Si-C bond length. It can be readily understood by the $\mathrm{V}_{\mathrm{Si}}-\mathrm{V}_{\mathrm{C}}$ geometrical structure, and an essential localization of the excitation in the defect vicinity (see the $L^{*}{ }_{3 S i 3 C}$ values in Table 2). Localization diagrams in Fig. 2 lead to the same conclusion. In Fig. 2 we used $\left\{L_{A}^{*}\right\}$ averaged over two components of the ${ }^{3} E$ transition. In the images, excitation indexes are shown by atomic spheres of radius proportional to corresponding $\left\{L_{A}^{*}\right\}^{1 / 3}$ value. It is worth noting that while the excitations are localized mostly in the defect vicinity, the total contribution of the first neighbor sphere for dangling atoms is far from negligible.

Notice also that another DFT functional used, M11, systematically gives the excitation energies only a bit lower $(\approx 0.1 \mathrm{eV})$ than CAM-B3LYP does, and all our ESSA results remain nearly the same as well.

In our previous TDDFT computations on the reasonably small nanodiamond with $\mathrm{NV}^{-}$ -center, $\mathrm{C}_{33} \mathrm{NH}_{36}{ }^{-}$, we have obtained $L^{*}=$ $77 \%$ for a summary excitation localization on respective dangling atoms, and $R_{\text {exc }}$ about $3.5 \AA$ at $r(\mathrm{C}-\mathrm{C}) \sim 1.5 \AA$. Thus, the lowest excitation of the $\mathrm{NV}^{-}$center is localized in a smaller atomic region. It might be related to a larger localization of frontier MOs in the case of charged defects, but it should be additionally examined.

\section{Conclusions}

In this note, we have reported some preliminary results related to computation and analysis of the lowest excited states in nano$\mathrm{SiC}$ paramagnetic color centers. For this purposes we employed our ESSA technique in the framework of the conventional TDDFT technique. As in the earlier studies of nanodiamond color centers, the lowest electronic transitions are significantly localized in the defect vicinity. This is not so surprising if taking into account that frontier MOs (which most contribute to the lowest excitations) are normally well localized just near defects. Actually, the very fact of strong orbital localizations, when impurity atoms or vacancy centers occur, is well known long ago [28], and the given quantum-chemical modeling supported and clarified these expectations for triplet excitations in the carborundum nanostructures by using the current advanced theoretical machinery. Strictly speaking, as previously for the defected nanodiamonds, we also should investigate the orbital localization in nano-SiC, say in the same manner as in [29]; this is also among our plans for the future. Furthermore, we showed that by using valence-like MCP approach we were able to perform economical computations of TDDFT equations which are very time/memory consuming. We believe that the MCP approach used may essentially expand our possibilities in ESSA/TDDFT applications to more complex nano-SiC networks.

Acknowledgement. This research was supported in part by the Ukrainian Foundation of Fundamental Studies (Grant No. F73/107-2016) and the Belorusian Republican Foundation for Fundamental Research (Grant No. X16K-055). 


\section{References}

1. J.Wrachtrup, F.Jelezko, J.Phys.:Condens. Matter., 18, S807 (2006).

2. J.Fan, P.K.Chu, Silicon Carbide Nanostructures: Fabrication, Structure, Springer, Berlin (2014).

3. Optical Engineering of Diamond, ed. by C.R.P.Mildren, J.R.Rabeau, Wiley, Berlin (2013).

4. P.Potasz, M.Korkusinski, P.Hawrylak, Graphene Quantum Dots, Springer-Verlag Berlin Heidelberg (2014).

5. Quantum Information Processing with Diamond, ed. by S.Prawer, I.Aharonovich, Elsevier LTD, Cambridge (2014).

6. A.L.Falk, B.B.Buckley, G.Calusine et al., $\mathrm{Na}$ ture Commun., 4, 1819 (2013).

7. V.A.Soltamov, P.G.Baranov, Uspechi Fiz. Nauk, 59, 605 (2016).

8. H.Seo, A.L.Falk, P.V.Klimov et al., Nature Commun., 7, 12935 (2016).

9. A.V.Luzanov, in: Practical Aspects of Computational Chemistry IV, ed. by J.Leszczynski, M.K.Shukla, Springer, New York (2016), p.151.

10. A.V.Luzanov, F.Plasser, A.Das, H.Lischka, J. Chem.Phys., 146, 064106 (2017).

11. A.P.Nizovtsev, S.Ya.Kilin, A.L.Pushkarchuk et al., New J.Phys., 16, 083014 (2014).

12. A.P.Nizovstev, A.Pushkarchuk, S.A.Kuten et al., Proc.Nat.Acad.Sci.Belarus. Phys. Math Ser., No. 1, 98 (2017).

13. A.V.Luzanov, O.A.Zhikol, Functional Materials, 23, 63 (2016).
14. A.V.Luzanov, O.A.Zhikol, I.V.Omelchenko et al., Functional Materials, 23, 268 (2016).

15. A.V.Luzanov, Functional Materials, 24, 127 (2017).

16. A.V.Luzanov, Functional Materials, 24, 434, (2017).

17. Fundamentals of Time-dependent Densityfunctional Theory, ed. by M.A.L.Marques, N.Maitra et al., Lecture Notes in Physics, Springer, Berlin (2012).

18. I.G.Kaplan, The Pauli Exclusion Principle: Origin, Verifications and Applications, John Wiley \& Sons, Chichester (2017).

19. A.V.Luzanov, Russ.Chem.Rev., 49, 1033 (1980).

20. A.V.Luzanov, O.A.Zhikol, Int.J.Quantum Chem., 110, 902 (2010).

21. A.V.Luzanov, O.A.Zhikol, in: Practical Aspects of Computational Chemistry I, ed. by J.Leszczynski, M.K.Shukla, Springer, New York (2012), p.415.

23. L.Gordon, A.Janotti, C.G.Van de Walle, Phys. Rev. B, 92, 045208 (2015).

24. M.Klobukowski, S.Huzinaga, Y.Sakai, in: Computational Chemistry: Reviews of Current Trends, Vol.3, ed. by J.Leszczynski, World Scientific, Singapore (1999), p,49.

25. T.Yanai, D.P.Tew, N.C.Handy, Chem. Phys. Lett., 393, 31 (2004).

26. R.Peverati, D.P.Truhlar, J.Phys.Chem.Lett., 2, 2810 (2011).

27. M.W.Schmidt, K.K.Baldrige, J.A.Boatz et al., J.Comput.Chem., 14, 1347 (1993).

28. M.Lannoo, J.Bourgoin, Point Defects in Seiconductors. I.Theoretical Aspects, Springer, Berlin (1981).

29. A.V.Luzanov, Functional Materials, 23, 596 (2016). 